\title{
UNIDADE DE RECUPERAÇÃO PÓS-ANESTÉSICA: DIAGNÓSTICOS DE ENFERMAGEM FUNDAMENTADOS NO MODELO CONCEITUAL DE LEVINE
}

\author{
POST-ANESTHESIC RECUPERATION UNIT: NURSING DIAGNOSIS BASED IN LEVINE CONCEPTUAL FRAME
}

UNIDAD DE RECUPERACION POS-ANESTESICO: DIAGNÓSTICO DE ENFERMERÍA FUNDAMENTADO EN EL MODELO CONCEPTUAL DE LEVINE

\section{Rejane Scanagatta Basso ${ }^{1}$ Marister Piccoli ${ }^{2}$}

RESUMO: Diagnóstico de enfermagem é um tema relevante e atual, o objetivo deste estudo foi identificar os diagnósticos de enfermagem mais freqüentes na unidade de recuperação pós-anestésica. Para fundamentarmos o estudo optamos pelo modelo conceitual de Levine. A amostra foi composta por 15 pacientes com idade entre $21 \mathrm{e}$ 70 anos. Os dados foram coletados por meio de um instrumento que foi utilizado no acompanhamento de pacientes na primeira hora em que permaneceram na URPA. Na identificação dos diagnósticos de enfermagem utilizamos o processo de raciocínio diagnóstico descrito por RISNER (1986), que apontaram categorias as quais denominamos de acordo com a Taxonomia II da NANDA. O resultado evidenciou nove diagnósticos de enfermagem sendo que os que tiveram freqüência superior a $80 \%$ foram: temperatura corporal desequilibrada (hipotermia leve) (100\%), (Alto) risco para infecção (100\%), (Alto) risco para lesão por posicionamento perioperatório (100\%), interação social prejudicada (100\%), (alto) risco para função respiratória alterada $(93,33 \%$ e (alto) risco para aspiração (80\%). Este estudo nos permitiu identificar os diagnósticos de enfermagem com vistas a implementação da assistência e prevenção de complicações, objetivando atenção integral na referida unidade.

PALAVRAS-CHAVES: Diagnóstico de Enfermagem; Enfermagem Perioperatória; Filosofia em Enfermagem.

ABSTRACT: Diagnostic of nursing is na excellent na current subject, the objetive of this assignment was to identify the most frequent diagnostic of patients in the unit of post-anaesthetic recuperation. To base the present study we opted to the conceptual model of Levine.The sample was composed by fifteen patients of with age that range between 21 and 70 years. The date were collected by na instrument previously elaboratedthat was used in the accompaniment of the patients in the first hour they remained in the URPA. In the identification of the nursing diagnostic using the process of diagnostic reasoning described by RISNER (1986), that indicated categories in whitc they were denominated according to the taxonomy II by NANDA. The result evidenced nine diagnostic of nursing and the ones that obtained frequency higher than $80 \%$ were: Unbalanced body temperature (light hypothermia) (100\%), (higgh) risk for infection (100\%), (High) risk for injury because of the perioperative positioning $(100 \%)$, harmed social interaction $(100 \%)$, (High) risk for modified respiratory function $(93,33 \%)$, (high) risk for aspiraion (80\%). This study allowed identify that nursing diagnostic, for the implementation of complications about assistance and prevention, having in mind the target of total attention in the related unit.

KEYWORDS: Nursing Diagnosis; Perioperative Nursing; Philosophy, Nursing.

RESUMEN: Diagnóstico del de enfermeria es um tema actual excelente, el objetivo deste estudio foi identificar el diagnóstico más frecuente de pacientes en la unidad de la recuperación del pos-anestésico. Para embasar este estudio optamos el modelo conceptual de Levine. La muestra fue compuesta por quince pacientes com edad que se extienden entre 21 y 70 años. Los dados fueram recogidos por el instrumento que fue utilizado previamente en el acompañamiento de los pacientes sobre la primera hora que permanecían en el URPA. En la identificación del diagnóstico del oficio de enfermera usando el proceso del razonamiento de diagnóstico descrito por RISNER (1986), e las categorías indicadas fueron denominados según la taxonomía II por NANDA. El resultado evidenció el diagnóstico nueve del oficio de enfermera y de los que obtuvo frecuencia más arriba el de $80 \%$ era: Temperatura del cuerpo desequilibrada (hipotermia ligera) (100\%), riesgo para la infección (100\%), riesgo para lesión debido a la colocación perioperative (100\%), interacción social dañada (100\%), riesgo para la función respiratoria modificada (93.33 \%es), riesgo para el aspiracion (80\%). Este estudio permitido identifica ese diagnóstico del oficio de enfermera, para la puesta en práctica de complicaciones sobre ayuda y la prevención, teniendo en mente la atención total en la unidad relacionada.

PALABRAS CLAVES: Diagnóstico de Enfermería; Enfermería Perioperatoria; Filosofía en Enfermería.

\footnotetext{
${ }^{1}$ Enfermeira Assistencial da Unidade de Centro Cirúrgico, URPA e CME do Hospital Policlínica de Cascavel, Especialista em Enfermagem com Ênfase em Centro Cirúrgico pela Universidade Estadual do Oeste do Paraná - UNIOESTE. E-mail:rejanebasso@brturbo.com.br

${ }^{2}$ Enfermeira, Professora Assistente do Curso de Enfermagem da Universidade Estadual do Oeste do Paraná, UNIOESTE, Mestre em Enfermagem Fundamental pela EERP/USP. E-mail: maristerpiccoli@aol.com - Endereço para correspondência: Rua Paraná, 2447 , ap.18 Cascavel, Paraná
} 


\section{INTRODUÇÃO}

O Período de recuperação pós-anestésica é considerado crítico, uma vez que o paciente passa por um procedimento cirúrgico e recebe drogas anestésicas, exigindo vigilância constante da equipe cirúrgica.

A maior incidência de complicações anestésicas ou pós-operatórias imediata acontecem neste período, sendo que as mais freqüentes são as respiratórias e circulatórias (AVELAR, 1991).

De acordo com POSSARI (2003) os recente avanços da cirurgia e da anestesia, principalmente com o advento da monitorização invasiva, passaram a necessitar uma área que ofereça meios de recuperação anestésica cirúrgica e são visíveis as vantagens de uma Unidade de Recuperação Pósanestésica (URPA), pois além dos cuidados especiais aos pacientes existem benefícios, tais como: reduções da mortalidade pós-anestésica e pós-operatória; facilidade para o trabalho de rotina nas unidade de internações; sensação de maior segurança ao paciente e também a seus familiares e redução de possíveis acidentes e complicações pós-operatórias e pós-anestésicas.

Baseado nas considerações acima relatadas acreditamos ser necessário a enfatização na assistência de enfermagem pautada na detecção, atenção e prevenção das complicações que possam resultar do procedimento anestésico cirúrgico.

A utilização da taxonomia da North American Nursing Diagnostics Association (NANDA, 2002), prevê a adoção de uma forma de comunicação na enfermagem, seja no ensino, na pesquisa ou na assistência.

Os diagnósticos de enfermagem dos pacientes na URPA, elaborado com base nesta taxonomia, oferece fundamentação para determinar as intervenções de enfermagem facilitando a implementação da assistência. Assim é possível avaliar a necessidade de recursos e a qualidade da assistência de enfermagem, e, a partir desta avaliação, propor medidas para a modificação da pratica por meio de programas de educação continuada e implementação da sistematização da assistência de enfermagem (ROSSI et al. 2000).

A assistência de enfermagem ao paciente no período pós-anestésico é relacionada ao desenvolvimento das atividades de enfermagem já planejadas desde a saída do paciente da sala de cirurgia até o momento da alta do paciente da URPA. Embora a assistência no período pós-anestésico esteja relacionada às situações que envolvem o paciente no período perioperatório como um todo, cabe a equipe de enfermagem estar atenta a possíveis complicações que possam ocorrer ao paciente, como também a situações decorrentes do procedimento e não atendidas, partindo para uma complicação. Nesse sentido, a observação necessita ser constante até que as funções vitais estejam totalmente estabilizadas. Destacamos aqui que as particularidades de cada paciente precisam ser consideradas não somente nas alterações estruturais decorrentes do procedimento anestésico cirúrgico, mas também nas situações emocionais decorrentes do momento vivenciado.

Sendo assim, este estudo tevecomo objetivo realizar a identificação dos diagnósticos de enfermagem na unidade de recuperação pósanestésica, com vistas a possibilitar a prescrição de enfermagem nesta unidade permeada pela sistematização da assistência de enfermagem e fundamentada no modelo conceitual de Levine.

\section{APONTAMENTOS DA LITERATURA CONSULTADA}

\section{Unidade de Recuperação Pós-Anestésica}

O século da anestesia moderna começou no ano de 1846, historicamente na data de 16 de outubro do mesmo ano sendo considerada a data em que se realizou a primeira cirurgia com anestesia geral (THORWALD, 2002).

De acordo com o autor acima citado naquele dia, às 10 horas no anfiteatro do hospital geral de Masseachusetts em Boston o cirurgião John Collins Warren, realizava a extirpação de um tumor no pescoço de um rapaz de 17 anos. Ele foi anestesiado pelo dentista William Thomas Greem Morton, com éter, por meio de um inalador que foi idealizado por ele. $\mathrm{O}$ episódio não foi registrado, sendo que o fotógrafo foi acometido de um mal estar ao presenciar a intervenção cirúrgica. Mais tarde, o pintor Robert Hunchy idealizou a cena em um quadro, pintado em 1882. A prática de extrações dentárias sem dor, feitas pelo Dr. Morton, com a inalação de éter, foram um sucesso, em virtude disto, foi solicitado a sua demonstração naquele hospital, tendo a autorização para a prática, pois ela antevia a possibilidade das cirurgias sem dor.

Conforme relata THORWALD (2002), Morton não revelou o nome da substância química usada, dando o nome de "Letheon" (em grego, IHLGH, "esquecimento"), sendo obrigado posteriormente a revelar, por ordem da associação médica de Boston, que a substância usada era éter sulfúrico puro, condição esta, que Ihe valia a permissão para a realização de novas intervenções cirúrgicas sem dor.

Nos meios acadêmicos da época a insensibilidade à dor no momento da prática cirúrgica era considerada utopia, com exceção da China, a qual já utilizava a técnica da acupuntura. Outros recursos eram utilizados para amenizar a dor, como o caso da utilização de plantas, as quais possuíam efeitos sedativos e analgésicos concomitantemente. A hipnose e as bebidas alcoólicas, também faziam parte da relação de elementos curativos (THORWALD, 2002).

De acordo com REZENDE (2000), na idade média era utilizado um método de anestesia originado na escola de Alexandria, cuja fórmula foi divulgada na sua descoberta no mosteiro de Monte Casina. Tratavase de uma esponja soporífera, que era embebida com 
ópio, sucos de amoras amargas, euforbio, mermendio, mondragora, hera e sementes de cicuta. De acordo com o autor era utilizado aproximadamente $28 \mathrm{~g}$ de cada substância, após fervia-se e deixava-se evaporar por completo, colocava-se a esponja em água fervendo por uma hora e em seguida era colocado nas narinas do paciente até que este dormisse. Para que o mesmo acordasse, utilizava-se uma esponja com vinagre para ser inalado.

Joseph Prieslley descobriu o Dióxido de Nitrogênio $\left(\mathrm{NO}^{2}\right)$ em 1773 . Em 1796 coube a um aprendiz de farmácia chamado Humphry Dovy que residia na pequena cidade de Penzance, na Inglaterra, experimentar a inalação com $\mathrm{NO}^{2}$. Na ocasião foi observado que o gás produzia uma sensação agradável e uma vontade incontrolável de rir, foi dado o nome de gás hilariante ao dióxido. Em uma ocasião Joseph estava com dor de dente e ao inalar o $\mathrm{NO}^{2}$ sua dor desapareceu por completo, naquele momento ele deduziu que o $\mathrm{NO}^{2}$ suprimia a dor. Em um de seus escritos, com o título de Vapores Medicinais, sugeriu a utilização do gás em cirurgias, considerando que o mesmo parecia possuir a propriedade de acalmar as dores físicas, a medicina oficial não tomou conhecimento da sugestão (REZENDE, 2000).

O autor acima citado coloca que, Henry Hill Hichman, médico e cirurgião inglês, experimentava em animais o $\mathrm{NO}^{2}$ realizando pequenas operações, sem que estes demonstrassem qualquer sinal ou reação a dor. Hichman solicitou autorização da Royal Society e da Associação médica de Londres, para a realização da experiência em seres humanos. Seu pedido foi negado e ele foi considerado um visionário. Conforme relata o autor, Hichman escreveu ao rei da França como última tentativa e solicitou a Carlos $X$ para submeter o seu projeto do $\mathrm{NO}^{2}$ à avaliação da academia de Paris. Em sessão de 28 de setembro de 1828, convocada especialmente para este fim, a academia deu parecer negativo. Dois anos após, Hickman faleceu com apenas 29 anos de idade, sem ver em desenvolvimento o seu sonho da realização da intervenção cirúrgica sem dor.

De acordo com REZENDE (2000), Michael Faraday (1797-1867), físico inglês, estudando a liquefação de gases e os líquidos voláteis, descobriu que os vapores do éter possuíam efeitos inebriantes, semelhantes aos encontrados por Prieslley no Dióxido de Nitrogênio. Ao publicar uma nota no jornal Of Art And Schl na Inglaterra, chamou a atenção para o fato dos efeitos do éter produzirem insensibilidade total. Novamente os achados foram ignorados.

THORWALD (2002) coloca que nos Estados Unidos eram freqüentes os espetáculos públicos com a inalação de gás hilariante, assim como, as inalações de éter em reuniões reservadas conhecidas como ether parites. Em um desses espetáculos foi que Horace Wells, dentista na cidade de Hartfort, teve contato pela primeira vez com a substância. Constatou que o peróxido de nitrogênio $\left(\mathrm{NO}_{2}\right)$ possuía poder de causar insensibilidade e teve a idéia de utilizá-lo na realização de extrações dentárias. Solicitou então a um colega para que este extraísse um dente seu, fazendo experimentando, assim, em si próprio. Após a inalação com $\circ \mathrm{NO}_{2}$ não sentiu nenhuma dor e ainda teve uma sensação de euforia e bem-estar.

Conforme relata THORWALD (2002), Wells obteve permissão para que fizesse uma demonstração da aplicação da substância, para os professores e estudantes da Faculdade de Medicina de Harvard em Boston. Para que pudesse demonstrar foi necessária a participação de um estudante. Sua demonstração foi um fracasso, no transcorrer da mesma, o estudante gritou de dor e Wells foi convidado para que se retirasse da instituição de ensino e foi considerado pela comunidade acadêmica como sendo charlatão.

Em sua cidade, fez nova tentativa na qual aplicou uma maior quantidade da substância levando o paciente a uma parada respiratória, a qual quase o levou a óbito. Este fato foi de grande relevância, o qual culminou com o abandono de suas experiências e também de sua profissão.

THORWALD (2002) coloca que William Thomas Greem Morton obteve sucesso nas extrações dentárias sem dor, substituindo $\mathrm{NO}_{2}$ por éter, após ter consultado seu professor de química, Charles Thomas Jackson, o qual recomendou o uso de éter retificado e falou onde poderia obtê-lo. Os resultados dessa nova experiência foram um sucesso, superiores aos obtidos quando da aplicação do $\mathrm{NO}^{2}$.

Conforme o autor acima citado, Morton anteviu a possibilidade da cirurgia sem dor e conseguiu permissão para demonstrar a experiência no Massachusetts General Hospital. Assim, chegou-se ao dia 16 de outubro de 1846, data em que ficou registrada na história da medicina, como o marco inicial da cirurgia sem dor. Warrem relatou as seguintes palavras: "Daqui a muitos séculos, os estudantes virão a este hospital para conhecer o local onde se demonstrou pela primeira vez a mais gloriosa descoberta da ciência" (THORWALD, 2002, p.97).

REZENDE (2000) relata que esta não foi a primeira cirurgia realizada com anestesia geral por éter, na cidade de Jefferson, no estado da Geórgia nos Estados Unidos, em 1841, um médico chamado Crowford Willianson Long, realizava sessões de éther frolics em casa. Muitas vezes, após usar éter ele se machucava sem sentir dor e foi essa experiência empírica que o despertou para a observação minuciosa, diante do fato da substância causar-Ihe a insensibilidade à dor na parte do corpo que estivera em contato com o éter. A partir dessa constatação, Long passou a realizar pequenas cirurgias. A primeira realizada por ele foi em um amigo, sendo que esta foi presenciada por várias pessoas. Nesta ocasião ele retirou dois tumores da nuca de seu amigo sem que ele nada sentisse. Para ter certeza, Long amputou dois dedos de um escravo que havia se queimado, o primeiro sob o efeito do éter, e o segundo após ter cessado o seu efeito. O rapaz relatou ter sentido dor, somente quando da amputação do segundo dedo provando dessa forma a ação anestésica que o éter possuía.

Conforme descreve THORWALD (2002), Long realizou oito cirurgias sob o efeito do éter, mas não 
acreditava ser possível realizar grandes intervenções. Considerava que somente se o paciente inalasse éter durante todo o período em que estivesse sendo submetido à intervenção cirúrgica teria efeito, mas acreditava estar colocando em risco a vida do paciente, sendo assim, foi obrigado a abandonar a utilização do éter em suas cirurgias e a renuncia deuse através da solicitação de uma comissão local, segundo a qual, havia um temor da população de que na realização de alguma cirurgia pudesse ocorrer um óbito, o que culminaria inevitavelmente na revolta da comunidade que lá residia. Long abandonou suas experiências pioneiras, as quais tornar-se-iam conhecidas somente muitos anos depois.

$$
\text { Jackson, }
$$$$
\text { cirurgião }
$$

reconhecido internacionalmente, reivindicou para si nos países europeus a prioridade da descoberta relatando que este era desonesto. Wells, com o seu fracasso cometeu desatinos, como ser preso e posteriormente se suicidar na prisão, nesta ocasião estava ele com trinta e três anos de idade. Morton morreu subitamente em uma via pública aos quarenta e nove anos, pobre e desacreditado. Após sua morte houve um reconhecimento a seu favor, proveniente da população norte-americana onde foi construído um monumento no local de sua sepultura com os seguintes dizeres: "Aqui jaz W. T. G. Morton, o descobridor e inventor da anestesia. Antes dele, a cirurgia era sinônimo de angústia, por ele foram vencidas e aniquiladas as dores do bisturi. Depois dele, a ciência é senhora da dor." (REZENDE,2000, p.2-4).

De acordo com o autor acima citado, Jackson, após tomar conhecimento deste fato, sentiu-se derrotado e tornou-se alcoólatra, terminando sua vida num hospício onde morreu aos setenta e cinco anos em 1880. Long faleceu subitamente aos sessenta e três anos, arrependido de não ter divulgado sua descoberta, a qual precedeu a de Morton em quatro anos.

REZENDE (2000) relata que nos anos seguintes foram introduzidos novos agentes anestésicos, como o Clorofórmio, usado pela primeira vez em 1847 por James Simpson, em um trabalho de parto. Em 1930 o Ciclopropano, e em 1956 o halotano

Paralelamente à anestesia geral desenvolveram-se outros meios de analgesia sendo elas: anestesia local, sedação e a raquianestesia dentre outras. A anestesia geral chegou ao Brasil em 1847 no Hospital Militar do Rio de Janeiro, pelo Dr. Roberto Jorge Haddock Lobo. Em 1848 o éter foi substituído pelo Clorofórmio pelo professor Manuel Feliciano Pereira de Carvalho, na Santa Casa do Rio de Janeiro (REZENDE, 2000).

De acordo com REZENDE (2000), no século $\mathrm{XIX}$, nos Estados Unidos, os enfermeiros foram o primeiro grupo de anestesistas, considerados como a primeira especialidade de enfermagem clínica, desenvolvida em resposta a grande demanda de cirurgias. Alice Magaw, considerada "mãe da anestesia", documentou e divulgou, em vários jornais médicos, no período de 1899 a 1906, a idéia da formação de enfermeiros na prática da anestesia.
REZENDE (2000) coloca também que na primeira guerra mundial os enfermeiros treinavam também os médicos, além de outros enfermeiros, para que os mesmos estivessem habilitados para desenvolverem o procedimento anestésico. Foram os principais prestadores de serviços em anestesia, nas áreas de combate onde havia a participação dos Estados Unidos.

A regularização do ensino médico no campo da anestesia não aconteceu até a segunda guerra mundial, onde registrou-se sete residentes em anestesia, com prática de pelo menos um ano na especialização. Nessa guerra, haviam dezessete enfermeiros que atuavam na anestesia para cada anestesista médico. No Vietnã, eram três profissionais enfermeiros, para cada médico. No golpe do Panamá, foram somente profissionais anestesistas médicos e com certificado registrado. Hoje, no Brasil e no mundo, apenas profissionais médicos exercem a profissão de anestesiologistas (REZENDE, 2000).

De acordo com Nocite (1987) apud PENICHE (1998), a história da unidade de recuperação pósanestésica (URPA) teve início antes da descoberta da anestesia a aproximadamente 200 anos. Foi nos Estados Unidos onde se reservou uma sala menor ao lado da sala de operação para atender e dar cuidados especiais aos pacientes em estado crítico ou pacientes submetidos à cirurgias de grande porte. Em meados do século passado, houve relatos da existência deste local também implementado por Florence Nightingale. Em 1942 nos Estados Unidos utilizou-se pela primeira vez o termo "sala de recuperação pós-anestésica" (Nocite apud PENICHE, 1998, p.167).

$O$ progresso da medicina trouxe consigo a exigência das URPAs nas instituições hospitalares e a portaria 400 do Ministério da Saúde, de 06 de dezembro de 1977, prevê desde aquele ano o local em todas as unidades de centro cirúrgico, mas a obrigatoriedade da unidade somente foi estabelecida em 1993, por um Decreto Federal, com a Resolução CFM no 1363/93 (TAVARES, 1999).

Conforme relato do autor acima citado, para que o paciente seja melhor atendido, a URPA deve localiza-se o mais próximo do centro cirúrgico, facilitando o transporte do paciente e mantendo a estabilidade de seus sinais vitais após ser retirado da sala de cirurgia, exigindo total rapidez, atenção e acesso fácil da equipe cirúrgica nos casos de urgência.

Considerando a questão da localização, o espaço físico apropriado e os recursos materiais, existe a necessidade do planejamento de recursos humanos para que a assistência em URPA seja implementada, resultando em uma equipe multidisciplinar preparada para $\mathrm{O}$ atendimento especializado e individulizado (PENICHE, 1998).

Quanto a equipe de enfermagem, de acordo com a autora acima citada, ésta necessita ser composta por enfermeiros e técnicos de enfermagem e deve ser planejada de acordo com a quantidade de leitos na unidade e a complexidade dos procedimentos anestésicos cirúrgicos realizados na instituição. 
BELLO (2000) coloca que a alta do URPA é de responsabilidade do anetesiologista e necessita ser baseada em índices de avaliação que permitam o retorno seguro do paciente ao seu leito de origem.

ALDRET (1970), indicam um método de avaliação numérico para avaliar o estado geral do paciente após estes terem sido submetidos ao procedimento anestésico, tendo em vista todos os sinais e complicações que possam aparecer no decorrer de sua permanência na URPA.

Diante do que foi acima exposto acreditamos que a URPA depende da existência de assistência sistematizada, uma vez que esta permite verificar, ao longo do tempo, se as condutas adotadas, são eficazes e se permitem a prevenção de complicações neste período, considerando as especificidades do paciente e também dos procedimentos anestésicos e cirúrgicos, intermediado com o trabalho em equipe.

\section{Assistência Na Unidade De Recuperacão Pós- Anestésica}

A incidência das complicações no período pósoperatório imediato poderão estar associadas as condições do paciente no pré-operatório, as especificidades do procedimento cirúrgico, intercorrências no período trans-operatório e as medidas terapêuticas adotadas.

De acordo com KEARS (1989) todo procedimento anestésico traz consigo o potencial de gerar complicações, para que possamos atuar preventivamente é necessário conhecermos as complicações que o procedimento pode acarretar, assim iremos discorrer brevemente as comumentes encontrados em nosso meio profissional.

\section{Complicações Respiratórias.}

As complicações respiratórias são estatisticamente as principais causas de mortalidade e morbidade relacionada a anestesia e alguns fatores como: idade avançada, tabagismo, doenças pulmonares previas, obesidade, cirurgia torácica ou em abdômen superior podem aumentar consideravelmente 0 risco de complicações pulmonares relacionadas ao ato anestésico (MANICA et al. 1994).

A obstrução parcial ou completa das vias aéreas pode ocorrer a qualquer momento, sendo que a queda da língua é a causa mais freqüente de obstrução de via aérea alta, ocorrendo inconscientemente pelo relaxamento da musculatura do assoalho da boca e do maxilar inferior, impedindo a passagem do ar ao nível da hipofaringe, este esforço respiratório causa uma respiração ruidosa, que é solucionada com a hiper-extensão do pescoço, com projeção da mandíbula para frente e para cima, quando esta manobra não surgir efeito, é necessário o uso de cânulas oral ou nasofaringeanas (MANICA et al. 1994).

O decúbito lateral é o mais indicado na recuperação do paciente inconsciente pois, nesta posição a língua normalmente não causa obstrução de vias aéreas e esta posição também reduz o risco de aspiração de sangue e secreção, desde que não haja contra indicação pelo procedimento cirúrgico (MANICA et al. 1994).

\section{Complicações Relacionadas a Intubação e Extubação}

Estas complicações podem ocorrer em qualquer fase da intubação, sendo que neste momento podem ocorrer dificuldades devido ao trauma na orofaringe, intubação seletiva, instabilidade cardiovascular, aspiração, obstrução do tubo por corpo estranho, problemas relacionados ao balonete e desconexão do sistema. Na extubação os problemas mais freqüentes são: laringoespasmo, aspiração, instabilidade cardiovascular, dor na garganta e laringe (MANICA, et al, 1994).

A embolia Pulmonar "...é a complicação tardia no pós-operatório, especialmente nos pacientes com longa permanência no leito, que se submetem a um procedimento anestésico-cirúrgico de longa duração e com grande manipulação" (MANICA et al 1994, p.465), e qualquer partícula ou substancia insolúvel dentro de um vaso tem potencial para causar embolia nos pulmões.

Hipotecai é a diminuição da pressão parcial de oxigênio no sangue arterial $\left(\mathrm{PaO}_{2}\right)$ sendo que esta para a sua normalidade depende da idade, da fração inspirada de $\mathrm{O}_{2}\left(\mathrm{FiO}_{2}\right)$, da pressão parcial de $\mathrm{CO}_{2}$ no sangue arterial $\left(\mathrm{PaCO}_{2}\right)$ e da pressão barômica. A hiperventilação é a causa mais comum de hipoxemia na recuperação pós-anestésica (MANICA et al. 1994).

A hipercapmia "Ocorre quando a ventilação alveolar é insuficiente em relação à produção de $\mathrm{CO}_{2}$ (gás carbônico). É definida como um aumento da $\mathrm{PaCO}_{2}$, acima dos valores normais estimados" (MANICA et al. 1994, p.490-491) sendo que:

“(...) a depressão respiratória central é a principal causa de aumento de $\mathrm{PaCO}_{2}$, no pósoperatório imediato, pode ser causada principalmente por sobredose de anestésicos, hiperventilação exagerada durante a anestesia, hipotermia, de modo especial em crianças de baixa idade, e lesões do sistema nervoso central (Isquemia, trauma, tumor)."

No caso de broncoespasmo, segundo MANICA et al. (1994) é necessário inicialmente fazer um diagnóstico diferencial entre 0 broncoespasmo verdadeiro e as causas que o simulam, uma vez que o termo broncoespasmo é usualmente utilizado para definir de modo abrangente os ruídos e sibilos que ocorrem durante a anestesia. No entanto, muitas são as situações que produzem estes ruídos, não estão diretamente relacionadas a uma contração da musculatura lisa bronquial, necessitando portanto de uma conduta terapêutica diferente. As simulações de broncoespasmos podem ser por obstrução das vias aéreas por tubo endotraqueal dobrado ou obstruído, 
presença de secreção na árvore traqueobrônquica e edema de vias aéreas.

Segundo MANICA et al. (1994) a aspiração do conteúdo gástrico é uma complicação potencialmente fatal em anestesia, podendo ocorrer em qualquer momento da anestesia, foi descoberto por Mendelson em 1946, que associou as manifestações clinicas encontradas, a aspiração do conteúdo gástrico. Os pacientes que oferecem maior risco são: com obstrução intestinal, abdômen agudo, gestantes obesas, pacientes submetidos a cirurgia de emergência sem jejum adequado, traumatizados com lesões neurológicas, álcool e intoxicação por droga.

De acordo com os autores o diagnóstico é facilmente realizado quando se observa vomito e o conteúdo gástrico é aspirado através da traquéia, que pode ser regurgitado silenciosamente. As manifestações clínicas são predominantemente: cianoses, dispnéia, taquipnéia, sibilos e roncos a ausculta.

A recuperação pós-anestésica é algumas vezes um momento decisivo para o paciente cirúrgico, pois é neste espaço de tempo que este pode apresentar algumas alterações no estado geral que determinam o prosseguimento da recuperação do procedimento cirúrgico. O enfermeiro da URPA e a equipe necessitam de atenção para estes problemas uma vez que possam ser detectados precocemente e a assistência implementada. Relataremos a seguir algumas complicações que freqüentemente podem se fazer presentes nesta unidade

Segundo HOFFER (1997), as náuseas podem ser causadas pelo estimulo do centro do vômito na medula por impulsos oriundos do trato gastrintestinal de outros centros cerebrais decorrentes de drogas.

Eles ocorrem mais freqüentemente em mulheres do que em homens, sendo que alguns fatores contribuintes podem ser: historia de intolerância aos movimentos, fase do ciclo menstrual, dor, medicamentos utilizados no perioperatório, técnicas anestésicas, distensão abdominal durante a cirurgia, local da cirurgia (abdômen superior e tórax), hipotensão perioperatória, insuficiência respiratória, obesidade, posicionamento do paciente e movimentos rápidos no transporte do paciente (HOFFER, 1997).

Segundo HOFFER (1997), a dor na recuperação pós-anestésica quando não tratada é constante queixa dos pacientes sendo que algumas vezes faz-se necessário uma quantidade adequada de anestésicos para o controle satisfatório da dor.

As medicações administradas na URPA devem ser IV (intravenosa) pois sua absorção é mais rápida, enquanto a IM (intramuscular) são retardadas $e$ altamente variadas. Medidas recentes de alívio da dor, incluem a administração de drogas anestésicas e narcóticas por cateteres intraespinhais e epidural. (HOFFER, 1997)

De acordo com HOFFER estudos demonstram que estas novas técnicas diminuem a estada do paciente hospital, e também a quantidade de drogas administradas.
$\mathrm{Na}$ primeira hora da recuperação pósanestésicas são comuns alterações na função neurológica como agitação e tremores. As causas mais comuns estão associadas a dor, disfunção respiratória, distensão gástrica ou urinária, desequilíbrio eletrolítico, abuso de drogas e fatores psicológicos persistentes. Normalmente estas alterações são resolvidas com o passar do tempo de recuperação e tratamento dos fatores contributivos (HOFFER, 1997).

Segundo HOFFER (1997), múltiplas arritmias cardíacas podem ocorrer no período pós-operatório, alguns fatores predisponentes como: doença cardiovascular preexistente, dor, hipotermia, disfunção respiratória resultando em hipóxia, alcalose e desequilíbrio hidroeletrolítico ou ácido básico.

A hipotensão é experimentada por cerca de 3\% dos pacientes no pós-operatório (FROST, 1992). A hipotensão tem sido definida como uma pressão arterial menor que $20 \%$ do nível basal ou que a pressão do pré-operatório. Muitas vezes os sinais clínicos da hipotensão são mais confiáveis como um indicador, especialmente no paciente com apenas um registro de pressão no pré-operatório.

Os sinais clínicos podem incluir: pulso rápido e filiforme, desorientação, sonolência, oligúria, pele fria e pálida. O débito cardíaco e a resistência vascular determinam a pressão arterial (HOFFER, 1997).

A hipotensão pode ser devida a disfunção cardíaca como: infarto do miocárdio, tamponamento, embolia ou medicações incluindo agentes anestésicos. Neste caso, o coração não estará bombeando eficazmente. $O$ oxigênio e estimulantes cardíacos poder ser usados quando necessários juntamente com a monitorizarão hemodinâmica (HOFFER, 1997).

A hipertensão arterial sistêmica é geralmente definida como uma pressão arterial maior que $20 \%$ do nível basal do paciente ou do pré-operatório. Se novo, os sinais clínicos são os mais importantes indicadores da gravidade da hipertensão. A cefaléia, alterações no estado mental e dor subexternal são todos indicadores de danos de um órgão-fim (HOFFER, 1997).

A hipertensão assintomática é uma ocorrência comum na URPA e é geralmente considerada como inofensiva e a solução é determinada, geralmente, pela causa. A pressão arterial elevada faz causar aumento da tensão na parede ventricular, pós-carga e trabalho miocárdico. O paciente com uma historia de doença cardíaca corre maior risco de resultados adversos e a hipertensão pode ser devida ao volume pré-carga ou edema pulmonar, que causa um aumento no débito cardíaco (HOFFER, 1997).

Segundo o autor, outras causa de hipertensão podem ser: dor, ansiedade, hipotermia, hipoxemia, hipercardia e distúrbio vesical. Os pacientes com dor são medicados e os pacientes com hipotermia são aquecidos, também são bem oxigenados e ventilados se necessário, para melhorar a hipoxemia ou hipercardia, os pacientes necessitam ser incentivados a urinar ou são cateterizados para esvaziar toda a bexiga (HOFFER, 1997). 


\section{Diagnóstico De Enfermagem}

O processo de enfermagem foi difundido por meio das escolas com sua implantação nos currículos e suas etapas foram incluídas na Lei $n^{\circ} 7.498$, de 25 de junho de 1986 que dispõe sobre o Exercício Profissional como competência do enfermeiro (BRASIL, 1986).

De acordo com PICCOLI (2000) embora tenhase alcançado algum êxito nos últimos tempos, percebe-se que os enfermeiros ainda buscam adaptar o processo de enfermagem, bem como a sua implementação nas instituições de saúde.

Para HORTA (1979), o processo de enfermagem caracteriza-se pelo inter-relacionamento e dinamismo de suas fases. Esses passos são seis: histórico de enfermagem; diagnóstico de enfermagem; plano assistencial; plano de cuidados ou prescrição de enfermagem e evolução.

Diante das etapas do processo acima relacionadas, destacaremos neste trabalho atenção especial ao diagnóstico de enfermagem por ser nosso objeto de estudo.

Conforme CARPENITO (1997) em 1973, realizou-se a primeira conferência sobre diagnósticos de enfermagem com 0 intuito de identificar 0 conhecimento de enfermagem e estabelecer um sistema de comunicação adequado. Desta conferência nasceu o National Group for the Classification of Nursing Diagnosis, composto por enfermeiros dos Estados Unidos e Canadá atuantes na prática, educação e pesquisa.

De acordo com Carpenito apud PICCOLI (2000) a autora acima citada em seu primeiro encontro em 1973, este grupo determinou uma força-tarefa para: reunir e disseminar informações sobre o diagnóstico de enfermagem; encorajar as atividades educacionais para a implementação dos diagnósticos incluindo a realização de conferências e outros; e, promover e organizar as atividades com o objetivo de continuar o desenvolvimento, a classificação e a testagem científica dos diagnósticos de enfermagem, incluindo conferências nacionais, a identificação de critérios para a aceitação dos diagnósticos, o levantamento de atividades de pesquisa e a exploração de métodos de classificação. Uma proposta de força-tarefa mais formal foi aprovada na quinta conferência nacional e o grupo passou a ser chamado North American Nursing Diagnosis Association (NANDA, 2002), a qual possui representantes eleitos para direção e comitês fixos.

Em 1987, a American Nurses Association (ANA) sancionou oficialmente a NANDA como a organização encarregada do sistema de classificação de diagnósticos de enfermagem (CARPENITO, 1997).

Em março de 1990, durante a nona conferência da NANDA, a assembléia aprovou uma definição oficial de diagnóstico de enfermagem como sendo:

Um julgamento clínico sobre as respostas do indivíduo, família ou comunidade aos problemas de saúde, processos vitais reais ou potenciais. $O$ diagnóstico de enfermagem proporciona a base para a seleção das intervenções de enfermagem, visando o alcance de resultados pelos quais a enfermeira é responsável (CARPENITO, 1997, p. 28).

A autora acima citada relata que a integração dos diagnósticos à prática é um processo coletivo e pessoal. Individualmente, cada profissional luta com seu raciocínio e confirmação diagnóstica.

CARPENITO (1997) coloca que os diagnósticos de enfermagem derivam de avaliações considerando que o paciente está a todo momento interagindo com o ambiente, e que o diagnóstico não pode ser retirado do contexto do processo de enfermagem, isto resultaria em mau uso do conceito e rotulação prematura a estereótipos, resultando em assistência inapropriada. Ressalta que, cada passo depende da exatidão do passo precedente e que a coleta de dados e a avaliação são relacionados ao diagnóstico, ao planejamento e a implementação. Sendo assim, a separação por passos é explicativa, pois na prática o processo é contínuo e suas fases são interrelacionadas e a aplicação coloca em prática as ações de enfermagem.

De acordo com CARPENITO (2003), na ultima década o desenvolvimento desta linguagem e a sua implementação na prática e educação tem evoluído rapidamente, sendo que a pratica da enfermagem freqüentemente apresenta interface com as praticas de outros profissionais de saúde.

Acreditamos que o uso de tal sistema pode acelerar as atividades de pesquisa e facilitar a comunicação entre a enfermagem, o paciente e os outros profissionais de saúde.

Desde a publicação da primeira edição da NANDA a utilização do diagnóstico de enfermagem cresceu consideravelmente nos Estados Unidos e Canadá. No Brasil, é um caminho que ainda está sendo percorrido nas instituições de saúde e muitas universidades já estão inserindo na grade curricular, sendo que a experiência com os diagnósticos de enfermagem para a sua implementação na prática varia da iniciação para a integração por aproximadamente quinze anos (CARPENITO, 1997).

De acordo com CARPENITO (2003), a elaboração de um diagnóstico de enfermagem exige conhecimento e prática e se for usado de forma sistemática, a exatidão será aumentada, uma vez que o ser humano é complexo, exclusivo e em constante mudança.

\section{Modelo Conceitual De Myra Strin Levine}

De acordo com LEONARD (1993), Levine não tinha intenção de desenvolver uma teoria de enfermagem, mas em 1969, após uma publicação em uma revista de enfermagem, foi referido este trabalho como uma teoria, mas ainda hoje ela prefere dizer que é um modelo conceitual.

A teoria de Levine se divide em Adaptação, conservação e integridade sendo que a adaptação é o 
processo de vida pelo qual ao longo do tempo as pessoas mantém sua integridade ou totalidade ao reagir com o ambiente, e a conseqüência da interação da pessoa e do ambiente (GEORGE, 2000).

A conservação é o produto da adaptação que tem um conceito universal, é uma lei natural que trata da totalidade e integridade do sistema sendo que na enfermagem a atuação na conservação é auxiliar a pessoa a manter-se única e total, através do mínimo esforço despedido e divide-se em quatro princípios que são: conservação de energia, conservação da integridade estrutural, conservação da integridade pessoal e conservação da integridade social (LEONARD, 1993).

Segundo Levine apud PICCOLI \& GALVÃO (2004), os processos da vida exigem uma constante troca de energia, e não pode haver um equilíbrio absoluto de energia no sistema vivo, porque os sistemas de produção de energia no corpo físico são sistemas químicos, e um equilíbrio químico ocorre somente com a morte. Relata também que a habilidade do corpo humano desempenhar o trabalho da vida é dependente do seu balanço de energia, a soma de nutrientes de produção de energia medida contra a vazão de atividades de uso de energia.

Para a autora acima citada todas as pessoas que já estiveram doentes, mesmo um resfriado comum, sabem que aparecem características e fadiga que fazem necessária a limitação de atividades. A energia exigida pelas alterações na função fisiológica durante a doença representa uma exigência adicional feita nos sistemas de produção de energia, e a fadiga tão freqüentemente sentida com a doença é uma medida empírica da demanda adicional de energia. Um aumento na temperatura do corpo sinaliza um aumento na vazão de produção de energia, sendo que para cada aumento de grau na temperatura do corpo ocorre um aumento de $7 \%$ no metabolismo.

$\mathrm{Na}$ conservação da integridade estrutural, Levine apud PICCOLI \& GALVÃO (2004) afirma que todos os procedimentos cirúrgicos são realizados para restaurar a integridade estrutural para todo o corpo, mesmo quando ocorre a amputação de uma parte ferida ou doente, ela entende que a integridade estrutural é restaurada quando a cicatriz é finalmente parte integrante dentro da continuidade da parte afetada. A autora acrescenta, que muitos ferimentos ou doenças curam sem deixar marcas, o que significa que não restará cicatriz visível e que muitos processos só estarão recuperados com a retirada dos pontos e eliminação das células mortas que fizeram parte do processo de cicatrização, neste caso, não poderá haver maiores problemas com a função da estrutura.

Para a autora, a conservação da integridade estrutural é a defesa necessária do todo anatômico e fisiológico e é a base para as intervenções de enfermagem.

O principio de conservação da integridade pessoal caracteriza que em todo indivíduo, o senso de identidade é a mais completa evidência de totalidade e existe sempre uma privacidade da vida do indivíduo que é dividida através de experiência comum, mas a decisão de dividir ou não é sempre uma expressão de privacidade de alguém. A necessidade do indivíduo de assumir a responsabilidade pelas próprias decisões desenvolve-se com o processo gradativo de crescimento e desenvolvimento, e mesmo a criança, aprende a tratar com respeito o direito de tomar algumas decisões que são dela (Levine apud PICCOLI \& GALVÃO 2004).

Para a autora são poucas as experiências de vida que representam uma grande ameaça para o prazer próprio do que um episódio de doença, e particularmente quando este episódio requer hospitalização e uma vez reconhecida a necessidade de submeter-se aos cuidados de outras pessoas, o indivíduo já sente o temor da perda de sua independência e pode ameaçar sua habilidade em tomar decisões sozinho e coloca também que o respeito do enfermeiro é essencial para o auto-respeito do paciente, e isto deve incluir a boa vontade de permitir que o paciente tome decisões sozinho quando possível, e ele (o enfermeiro) necessita auxiliar nas decisões, e mais ainda, que a censura moral não tenha lugar no cuidado de enfermagem. A integridade pessoal do paciente deve ser guardada e defendida pelo enfermeiro.

Quanto a conservação da integridade social Levine apud PICCOLI \& GALVÃO (2004), a vida do indivíduo somente tem sentido no contexto da vida social, todo indivíduo divide seu tempo em comunidades sociais, seja ela na família, no emprego, com amigos, igreja, grupos étnicos, cidades, vilas, estado ou nação, e em tempo de comunicação, com o mundo. Para a autora os modos nos quais o indivíduo se relaciona com um destes grupos, influencia seu comportamento, existem tipos de relações que caraterizam a vida em casa, que é diferente daquela nos grupos públicos e nenhum indivíduo pode reconhecer o seu todo sem que esteja envolvido com outros seres humanos.

Para a autora as forças que vêm das relações humanas são necessárias quando os episódios de doença acontecem, e freqüentemente a família é profundamente afetada pelas mudanças que podem resultar da doença, as vezes esses períodos são longos, e , muitas vezes pode isolar o paciente de sua família e seus amigos por longos períodos, coloca também que os enfermeiros pertencem ao meio social hospitalar e que os pacientes são dependentes da boa conduta e preocupação da equipe, a atitude de que o paciente vem em primeiro lugar tem servido como meio para excluir os membros da família da genuína interação com o paciente. A autora acrescenta que este tem sido um problema difícil nas unidades de cuidado intensivo onde as necessidades do paciente são colocadas em prioridade, mas freqüentemente sobre preocupação e medo dos parentes e sendo assim, em alguns momentos na hospitalização ocorre falha em não considerar a família e os amigos, não somente a exclusão da família cria problemas emocionais para o paciente e sua família, mas também a contribuição que a família pode dar para o cuidado 
do paciente após a hospitalização não é considerada por alguns profissionais de saúde.

Os quatro princípios de conservação propostos por Levine segundo LEONARD (1993), servem como fundamento a todas as ações de enfermagem, e para nós, acreditamos ser um modelo que atende as necessidades do paciente cirúrgico, pois além de se preocupar com a integridade estrutural em virtude de todos os riscos que o paciente passa ao ser submetido a um procedimento anestésico cirúrgico, preocupa-se também com a presença da família como sendo um elo importante no processo de recuperação das energias gastas sejam elas psicológicas ou fisiológicas.

Frente ao exposto, selecionamos o modelo conceitual de Levine para fundamentarmos a presente investigação na unidade de recuperação pósanestésica uma vez que este mesmo modelo já foi utilizado por PICCOLI \& GALVÃO (2004) no período Pré-operatório.

\section{OBJETIVO}

Identificar os diagnósticos de enfermagem na unidade de recuperação pós-anestésica em pacientes adultos, que se submeteram a procedimento anestésico cirúrgico geral, de pequeno e médio porte.

\section{METODOLOGIA}

Este estudo foi desenvolvido em um hospital com atendimento público e privado, de médio porte, localizado na cidade de Cascavel no estado do Paraná. A unidade é composta de seis salas cirúrgicas, uma unidade de recuperação pósanestésica (com três leitos) e duas salas obstétricas. A unidade de centro cirúrgico atende a todas as especialidades, inclusive cirurgias cardíacas, neurocirurgias, transplantes renais e de córneas. $O$ volume cirúrgico é, em media de quatrocentas e cinqüenta cirurgias mês.

A direção do serviço de enfermagem e direção clínica foram consultadas quanto à viabilidade da realização do presente estudo e esclarecida quanto ao seu desenvolvimento.

A amostra constou de quinze pacientes adultos que foram submetidos a procedimento cirúrgico geral de pequeno e médio porte que foram consultados e esclarecidos através de termo de consentimento por escrito ainda no período pré-operatório, garantindo o direito de desistirem da participação, assim como o completo anonimato.

O projeto do presente estudo foi encaminhado ao Comitê de Ética em Pesquisa da Universidade Estadual do Oeste do Paraná, o qual foi avaliado e aprovado conforme Protocolo $\mathrm{n}^{\circ}$ 008889/03.

Este estudo foi desenvolvido com o seguinte percurso: Elaboração de um instrumento de coleta de dados fundamentado no modelo conceitual de Levine, na literatura pesquisada e na experiência profissional dos pesquisadores. Com a finalidade de obtermos subsídios para verificarmos a adequação e a forma de aplicação do instrumento, foi realizado um teste piloto e nenhum ajuste foi necessário. A coleta de dados foi realizada por meio do acompanhamento dos pacientes na unidade de recuperação pós-anestésica por um período de uma hora, utilizando o instrumento elaborado, sendo que esta ocorreu nos meses de agosto e setembro de 2003. Após a coleta de dados procedemos a identificação dos diagnósticos de enfermagem de cada paciente, utilizando o processo de raciocínio diagnóstico descrito por Risner (1986) sendo a análise e a síntese as etapas de processo. Após a análise e a síntese construímos as afirmativas diagnósticas tendo como referência a Taxonomia II da NANDA (2002) e Carpenito (2003).

\section{APRESENTAÇÃO E DISCUÇÃO DOS RESULTADOS}

\section{Caracterização Da Amostra}

Tabela 01 - Pacientes cirúrgicos entrevistados, segundo o sexo. Cascavel, 2003.

\begin{tabular}{l|c|c}
\hline Sexo & $\mathrm{N}$ & $\%$ \\
\hline Feminino & 11 & 73.33 \\
\hline Masculino & 04 & 17.67 \\
\hline Total & 15 & 100.00 \\
\hline
\end{tabular}

$\mathrm{Na}$ tabela 1, em relação a variável sexo, verifica-se uma desigualdade entre mulheres, que representam $73.33 \%$ e dos homens $17.37 \%$ dos entrevistados.

Tabela 02 - Pacientes cirúrgicos entrevistados, segundo a idade. Cascavel, 2003.

\begin{tabular}{l|c|c}
\hline Idade & $\mathrm{N}$ & $\%$ \\
\hline 21 a 30 & 1 & 6.66 \\
\hline 31 a 40 & 3 & 20.00 \\
\hline 41 a 50 & 4 & 26,67 \\
\hline 51 a 60 & 4 & 26.67 \\
\hline 61 a 70 & 3 & 20.00 \\
\hline Total & 15 & 100.00 \\
\hline
\end{tabular}


A distribuição dos pacientes por idade é observada na tabela 2 indicando que de 41 a 60 anos correspondem a $53.34 \quad \% \quad$ dos entrevistados

Tabela 03 - Pacientes cirúrgicos entrevistados, segundo o tipo de anestesia. Cascavel, 2003.

\begin{tabular}{l|c|c}
\hline Tipo de Anestesia & N & $\%$ \\
\hline Anestesia Geral & 10 & 66.67 \\
\hline Raquidiana & 3 & 20.00 \\
\hline Geral mais Raquidiana & 2 & 13.33 \\
\hline Total & 15 & 100.00 \\
\hline
\end{tabular}

Dos pacientes cirúrgicos entrevistados $80.00 \%$ dos pacientes foram submetidos ao procedimento anestésico geral, sendo que 2 cirurgias foram complementadas com anestesia raquidiana.

\section{Diagnósticos De Enfermagem Identificados}

A seguir apresentamos em ordem de freqüência os diagnósticos de enfermagem identificados em quinze pacientes acompanhados na unidade de recuperação pós-anestésica.

Tabela 04 - Diagnósticos de Enfermagem identificados nos pacientes entrevistados. Cascavel, 2003.

\begin{tabular}{l|c|c}
\hline \multicolumn{1}{c|}{ Diagnóstico de Enfermagem } & $\mathrm{N}$ & $\%$ \\
\hline Temperatura Corporal Desequilibrada (Hipotermia Leve) & 15 & 100.00 \\
\hline Alto Risco para Infecção. & 15 & 100.00 \\
\hline Alto Risco para lesão por posicionamento perioperatório & 15 & 100.00 \\
\hline Interação social prejudicada & 15 & 100.00 \\
\hline Alto Risco para Função Respiratória Alterada & 14 & 93.33 \\
\hline Alto Risco para Aspiração & 12 & 80.00 \\
\hline Mucosa Oral Alterada & 5 & 33.33 \\
\hline Integridade da Pele Prejudicada & 3 & 20.00 \\
\hline Senso e Percepção Alterado & 2 & 13.33 \\
\hline
\end{tabular}

A análise geral da freqüência demonstra que a hipotermia leve $(100 \%)$, risco para infecção $(100 \%)$, risco para lesão por posicionamento perioperatório $(100 \%)$ e interação social prejudicada $(100 \%)$ são diagnósticos preponderantes na amostra, tendo em vista que os mesmos foram identificados em todos os pacientes.

Ë importante mencionar que os diagnósticos de risco para função respiratória alterada e risco para aspiração também são relevantes, pois todos os pacientes com estes diagnósticos foram submetidos à anestesia geral o que levou a identificação destes diagnósticos.

A seguir, apontaremos os enunciados diagnósticos das categorias diagnósticas que obtiveram freqüência acima de $80 \%$ identificadas na presente investigação

Tabela 05 - Pacientes cirúrgicos entrevistados segundo o enunciado da categoria diagnóstica (Alto) Risco de Infecção. Cascavel, 2003.

\begin{tabular}{l|c|c}
\hline \multicolumn{1}{c|}{ Enunciados Diagnósticos } & $\mathbf{n}$ & $\%$ \\
\hline $\begin{array}{l}\text { (Alto) risco de infecção: relacionado ao local de invasão dos organismos } \\
\text { secundários à cirurgia, e procedimentos invasivos (intubação, anestesia } \\
\text { geral, tricotomia e venopunção). }\end{array}$ & 11 & 73.33 \\
\hline $\begin{array}{l}\text { (Alto) risco de infecção: relacionado ao local de invasão dos organismos } \\
\text { secundários à cirurgia e procedimentos invasivos (tricotomia e } \\
\text { venopunção). }\end{array}$ & 2 & 13.33 \\
\hline $\begin{array}{l}\text { (Alto) risco de infecção: relacionado ao local de invasão dos organismos } \\
\text { secundários à cirurgia e procedimentos invasivos (intubação, anestesia } \\
\text { geral e venopunção). }\end{array}$ & 1 & 6.67 \\
\hline $\begin{array}{l}\text { (Alto) risco de infecção: relacionado ao local de invasão dos organismos } \\
\text { secundários à cirurgia, e procedimentos invasivos (anestesia raquidiana, }\end{array}$ & 1 & 6.67 \\
\hline
\end{tabular}




\begin{tabular}{l|c|c}
\hline tricotomia e venopunção) & & \\
\hline Total & 15 & 100.00 \\
\hline
\end{tabular}

"Alto risco para infecção é o estado em que o indivíduo está em risco de ser invadido pôr um agente oportunista ou patogênico (vírus, fungos, bactérias, protozoário ou outros parasitas) de origem endógena ou exógena" (CARPENITO, 1997, p.357).

"Estar em risco aumentado de ser invadido pôr organismos patogênicos" (NANDA, 2002, p.134).

Este diagnóstico descreve um indivíduo cujas defesas hospedeiras estão comprometidas, ameaçando assim, a sensibilidade aos patógenos ambientais ou sua própria flora endógena (ADAMES, 2002).

O diagnóstico de alto risco de infecção foi identificado em quinze pacientes (100\% da amostra), sendo que os fatores de risco foram os procedimentos invasivos (tricotomia, intubação, anestesia geral, venopunção e anestesia raquidiana) e o procedimento cirúrgico.

O diagnóstico de enfermagem (alto) risco de infecção foi introduzido na taxonomia da NANDA em 1986, recebendo a classificação $n^{\circ} 1.2 .1 .1$ do "padrão de resposta humana trocar", que envolve o metabolismo do organismo em um processo de permuta com o meio físico, onde ocorrem a captação, a transformação e a eliminação de elementos (CRUZ \& CRUZ, 1991).

No presente estudo, foi constado que o procedimento cirúrgico e os procedimentos invasivos incluindo a anestesia geral, intubação, tricotomia e venopunção foram os de maior freqüência na amostra.

CARPENITO (1997), coloca que pele lesada leva duas vezes mais tempo para cicatrizar nos adultos devido à taxa de menor proliferação epidérmica.

Segundo Cruz et al apud PICCOLI (2000), o procedimento invasivo, caracterizado pela incisão cirúrgica, punções, tricotomia, intubação entre outros, constitui-se em fonte de infecções pela perda de barreira protetora (pele) devido ao procedimento invasivo.

Consideramos que este diagnóstico de enfermagem está relacionado ao modelo conceitual de Levine nos quatro princípios de conservação.

Tabela 06 - Pacientes cirúrgicos entrevistados segundo o enunciado da categoria diagnóstica Temperatura Corporal Desequilibrada (Hipotermia Leve). Cascavel, 2003.

\begin{tabular}{l|c|c}
\hline \multicolumn{1}{c|}{ Enunciados Diagnósticos } & $\mathbf{n}$ & $\%$ \\
\hline $\begin{array}{l}\text { Temperatura corporal desequilibrada (Hipotermia Leve): relacionado e } \\
\text { exposição ao ambiente frio, uso de medicações vasodilatadoras e } \\
\text { metabolismo diminuído. }\end{array}$ & 14 & 93.33 \\
\hline $\begin{array}{l}\text { Temperatura corporal desequilibrada (Hipotermia Leve): relacionada e } \\
\text { exposição a um ambiente muito frio, uso de medicações vasodilatadoras, } \\
\text { metabolismo diminuído e extremidades frias }\end{array}$ & 1 & 6.67 \\
\hline Total & 15 & 100.00
\end{tabular}

$\mathrm{Na}$ tabela acima, demonstramos os enunciados diagnósticos da categoria diagnóstica de hipotermia (Leve), que obteve $100 \%$ de freqüência nos pacientes entrevistados

No caso da identificação deste diagnóstico, o mesmo necessita de comunicação urgente para o tratamento de reaquecimento.

A prescrição de enfermagem para hipotermia leve deve iniciar assim que a situação for identificada, prevenindo o agravamento (CARPENITO, 1997).

De acordo com a autora citada, o organismo humano tem dois compartimentos, o externo e o interno. A transferência os envolve possibilitando que o externo esteja frio e o interno quente, ou vice-versa, sendo que a regulação da temperatura corporal envolve quatro mecanismos que são: condução, convecção, radiação e evaporação.

Para SMELTZER \& BARE (2002) durante o procedimento anestésico a temperatura do paciente pode cair, considerando que o metabolismo da glicose fica reduzido e conseqüentemente pode acarretar em acidose metabólica.

Este distúrbio denominado de hipotermia pode acontecer em uma sala cirúrgica ou URPA com baixa temperatura, infusão de líquidos frios, inalação de gases frios, feridas corporais ou cavidades abertas, atividade corporal diminuída, idade avançada ou pelos agentes farmacológicos utilizados (vasodilatadores, fenotiazinas e anestésicos gerais).

A hipotermia pode ser em alguns casos intencionalmente reduzidas para a redução da taxa metabólica do paciente.

Considerando os pacientes observados durante o procedimento cirúrgico podemos relacionar os diagnósticos identificados Temperatura Corporal Desequilibrada (hipotermia leve) com a temperatura ambiental, a exposição da cabeça, da face, das mãos e dos pés, sendo que essas áreas são vascularizadas por onde o calor é conduzido dos vasos sangüíneos para a pele e desta para o ar, e onde o frio é conduzido do ar para a pele e desta para os vasos sangüíneos.

Outro fator também considerado durante o período trans-operatório está relacionado à infusão de grandes quantidades de líquidos endovenosos frios e gases anestésicos.

Frente ao exposto entendemos a identificação do diagnóstico na expectativa da prevenção de 
agravos durante e após o procedimento anestésico cirúrgico.

Para estudos futuros consideramos um maior aprofundamento na verificação da temperatura retal e verificação também da pele nas extremidades inferiores, sendo que, no atual estudo somente foi realizada a verificação da pele nos membros superiores.

Consideramos que o presente diagnóstico de enfermagem está relacionado ao modelo conceitual de Levine no princípio de conservação de energia.

Tabela 07 - Pacientes cirúrgicos entrevistados segundo o enunciado da categoria diagnóstica (Alto) Risco para Lesão pôr Posicionamento perioperatório. Cascavel, 2003.

\begin{tabular}{l|c|c}
\hline \multicolumn{1}{c|}{ Enunciados Diagnósticos } & $\mathbf{n}$ & $\%$ \\
\hline $\begin{array}{l}\text { (Alto) risco para lesão por posicionamento perioperatório: relacionado à } \\
\text { exigência de posicionamento durante a cirurgia, perda das medidas } \\
\text { protetoras habituais sensoriais (anestesia geral) }\end{array}$ & 9 & 60 \\
\hline $\begin{array}{l}\text { (Alto) risco para lesão por posicionamento perioperatório: relacionado à } \\
\text { exigência de posicionamento durante a cirurgia, perda das medidas } \\
\text { protetoras habituais sensoriais (anestesia raquidiana) }\end{array}$ & 3 & 20 \\
\hline $\begin{array}{l}\text { (Alto) risco para lesão por posicionamento perioperatório: relacionado à } \\
\text { exigência de posicionamento durante a cirurgia, perda das medidas } \\
\text { protetoras habituais sensoriais (anestesia geral mais raquidiana) }\end{array}$ & 3 & 20 \\
\hline Total & 15 & 100.00
\end{tabular}

Na tabela acima, demonstramos os enunciados diagnósticos para (alto) risco para lesão por posicionamento perioperatório, que obteve $100 \%$ de freqüência.

Alto risco para lesão por posicionamento perioperatório "é o estado em que o indivíduo está em risco para lesão resultante das exigências de posicionamento para a cirurgia e da perda das reações protetoras habituais secundárias a anestesia" (CARPENITO, 1997 p.386).

"Alto risco para lesão por posicionamento perioperatório é estar em risco de lesão como resultado das condições ambientais encontradas no cenário perioperatório" (NANDA, 2002 p.145).

De acordo com CARPENITO (1997), os efeitos fisiológicos do posicionamento dependem de cada posição específica, e considera como um fator para lesão os procedimentos cirúrgicos que exigem duas horas ou mais de posicionamento. O posicionamento em geral afeta o sistema cardiovascular, respiratório, neurológico e tegumentar.

Durante o posicionamento o sistema músculoesquelético do paciente pode estar vulnerável, quando os agentes anestésicos deprimem os receptores da dor e pressão, ocorre a perda do tônus muscular, relaxamento muscular e os mecanismos de defesa não podem proteger o organismo (SMELTZER \& BARE, 2002).

CARPENITO (1997), afirma que as pessoas obesas têm mais risco de lesão por posicionamento cirúrgico devido a alguns fatores como a dificuldade para levanta-las até a posição, o tecido maciço e as áreas de pressão necessitam de ferro extra, a duração da cirurgia pode ser prolongada devido aos mecanismos de manipulação do tecido adiposo.

Tendo em vista o modelo conceitual de Levine, acreditamos que nesse caso o diagnóstico de enfermagem está inserido no princípio de conservação da integridade estrutura.

Tabela 08 - Pacientes cirúrgicos entrevistados segundo o enunciado da categoria diagnóstica interação social prejudicada. Cascavel, 2003.

\begin{tabular}{l|c|c}
\hline \multicolumn{1}{c|}{ Enunciados Diagnósticos } & $\mathbf{n}$ & $\mathbf{\%}$ \\
\hline Interação social prejudicada relacionada ao isolamento & 15 & 100.00 \\
temporário devido à permanência na recuperação pós- & & \\
anestésica, barreiras ambientais e de comunicação. & & 100.00 \\
\hline Total & 15 & 100 \\
\hline
\end{tabular}

Interação social prejudicada "É o estado em que o indivíduo apresenta, ou está em risco para apresentar respostas negativas, insuficientes ou insatisfatórias a interação" (CARPENITO, 1997, p. 596).

Interação social prejudicada: "Qualidade insuficiente ou excessiva ou qualidade ineficaz de troca social" (NANDA, 2002, p. 138).

CARPENITO (1997), considera que as interações sociais afetivas dependem da auto-estima positiva. Nenhum dado sugere que as pessoas tenham menos auto-estima, se compararmos com pessoas mais jovens. Embora, em pessoas idosas as ameaças comuns à auto-estima incluem a desvalorização, a dependência, as deficiências funcionais e o senso de controle diminuído.

Segundo a NANDA (2002), a incapacidade verbalizada ou observada para receber ou comunicar uma sensação satisfatória de pertencer, de contar, de interar-se ou ter uma história compartilhada, não 
podendo comunicar-se com a família pois em algumas recuperações pós-anestésicas estas informações não são repassadas.

Em nossa experiência, observamos a ansiedade dos pacientes na URPA ao despertarem da anestesia para que a família seja avisada do término do procedimento, ao mesmo tempo, a família fica na unidade de internamento sem ter nenhuma informação sobre o que está acontecendo, se o procedimento já terminou ou se seu familiar passa bem. Consideramos a necessidade de um sistema de informações através do enfermeiro da URPA junto à família, pois este intercâmbio de informações facilitaria a diminuição da ansiedade em ambos os lados, tornando assim, o paciente mais tranqüilo para sua recuperação pósoperatória.
Segundo a NANDA (2002), os fatores relacionados à integridade social prejudicada mostram isolamento temporário ao qual os pacientes pesquisados tem na sua maioria este isolamento devido ao tempo de permanência na recuperação pósanestésica, o qual fica sem poder comunicar-se com a família e a mesma sem saber noticias sobre o paciente.

De acordo com o modelo conceitual de Levine este diagnóstico de enfermagem está relacionado ao princípio de conservação da integridade pessoal, ao princípio de conservação da integridade social e também dentro do princípio de conservação de energia uma vez que a ansiedade aumento o gasto de energia.

Tabela 09 - Pacientes cirúrgicos entrevistados segundo o enunciado diagnósticos da categoria de (Alto) Risco para Função Respiratória Alterada. Cascavel, 2003.

\begin{tabular}{|c|c|c|}
\hline Enunciados Diagnósticos & $\mathbf{N}^{\circ}$ & $\%$ \\
\hline $\begin{array}{l}\text { (Alto) risco para a função respiratória alterada: relacionado ao efeito } \\
\text { depressivo das drogas anestésicas no sistema cardiovascular e } \\
\text { respiratório }\end{array}$ & 6 & 42.88 \\
\hline $\begin{array}{l}\text { (Alto) risco para a função respiratória alterada: relacionado ao efeito } \\
\text { depressivo das drogas anestésicas no sistema cardiovascular e } \\
\text { respiratório, com uso de Oxigênio. }\end{array}$ & 3 & 21.42 \\
\hline $\begin{array}{l}\text { (Alto) risco para a função respiratória alterada: relacionado ao efeito } \\
\text { depressivo das drogas anestésicas no sistema cardiovascular e } \\
\text { respiratório, manifestado com dispnéia e uso de Oxigênio. }\end{array}$ & 2 & 14.28 \\
\hline $\begin{array}{l}\text { (Alto) risco para a função respiratória alterada: relacionado ao efeito } \\
\text { depressivo das drogas anestésicas no sistema cardiovascular e } \\
\text { respiratório, manifestado por dispnéia. }\end{array}$ & 1 & 7.14 \\
\hline $\begin{array}{l}\text { (Alto) risco para a função respiratória alterada: relacionado ao efeito } \\
\text { depressivo das drogas anestésicas no sistema cardiovascular e } \\
\text { respiratório, manifestado por dispnéia e palidez. }\end{array}$ & 1 & 7.14 \\
\hline $\begin{array}{l}\text { (Alto) risco para a função respiratória alterada: relacionado ao efeito } \\
\text { depressivo das drogas anestésicas no sistema cardiovascular e } \\
\text { respiratório, com uso de oxigênio e palidez. }\end{array}$ & 1 & 7.14 \\
\hline Total & 14 & 100.00 \\
\hline
\end{tabular}

Alto risco para a função respiratória alterada: "Estado em que o indivíduo está em risco para apresentar uma ameaça a passagem do ar através do trato respiratório e a troca de gazes $\left(\mathrm{O}^{2}-\mathrm{CO}^{2}\right)$ entre os pulmões e o sistema cardiovascular" (CARPENITO, 1997, p.511).

Segundo CARPENITO (1997), as diversas responsabilidades da enfermagem associadas aos problemas da função respiratória, incluem a prevenção de problemas, a redução ou eliminação dos fatores contribuintes dos problemas respiratórios, a monitoração do estado respiratório e o controle da disfunção respiratória aguda.

Para a autora acima citada, risco para a função respiratória alterada foi acrescentado à lista da
NANDA para descrever um estado no qual o completo sistema respiratório tenha sido afetado e não apenas áreas isoladas, como a desobstrução das vias aéreas ou a troca gasosa.

Segundo a NANDA (2002), reservas de energias diminuídas resultam em uma incapacidade do indivíduo de manter respiração adequada para sustentar a vida.

Neste sentido, acreditamos que conforme o modelo conceitual de Levine, este diagnóstico de enfermagem poderá ser justificado nos princípios de conservação de energia, integridade estrutural e integridade pessoal.

Tabela 10 - Pacientes cirúrgicos entrevistados segundo o enunciado diagnósticos da categoria de (Alto) Risco para Aspiração. Cascavel, 2003. 


\begin{tabular}{l|c|c}
\hline e da laringe e redução do nível de consciência secundária a anestesia & & \\
geral & 12 & 100.00 \\
\hline Total &
\end{tabular}

Alto risco para aspiração é "Estar em risco de entrada de secreção gastrintestinais, secreções orofaríngeas, sólidas ou fluidas nas vias traqueobrônquicas" (NANDA,2002 p.40).

Segundo CARPENITO (1997), a depressão do sistema nervoso central interfere no mecanismo posterior dos esfíncteres e também considera que os tubos endotraqueais causam o estreitamento dos esfincteres e deprimem os reflexos da regurgitação e da tosse.

De acordo com SMELTZER \& BARE (2002) alguns anestésicos podem produzir aumento da secreção, muco e saliva, podendo o paciente apresentar vômitos e regurgitações, justificando a rápida identificação do diagnóstico de enfermagem evitando complicações maiores.

Considerando o modelo conceitual de Levine acreditamos que o presente diagnóstico está relacionado ao princípio de conservação de energia e integridade estrutural.

\section{CONCLUSÃO}

Dentre os diagnósticos de enfermagem identificados encontramos quatro categorias diagnósticas que foram detectadas nos 15 pacientes acompanhados perfazendo um total de $100 \%$ que foram: Temperatura Corporal Desequilibrada (Hipotermia Leve) (Alto) Risco para Infecção, (Alto) Risco para Lesão por Posicionamento Perioperatório e Interação Social Prejudicada.

Nestes quatro diagnósticos encontrados a enfermagem poderá estar implementando na prevenção visualizando o paciente em sua totalidade.

$\mathrm{Na}$ identificação dos diagnósticos mais dois tiveram freqüência superior a 80 \% que foram: (Alto) Risco para Função Respiratória Alterada (93,33\%) e (Alto) Risco para Aspiração $(80,00 \%)$, nos dois os pacientes foram submetidos à anestesia geral.

Diante dos diagnósticos de enfermagem identificados nos reportamos ao modelo conceitual de Levine e percebemos que em alguns diagnósticos de enfermagem alguns princípios estão claros, mas que na grande maioria necessitamos considerar a presença dos quatro princípios em todos os pacientes, uma vez que visualizamos a assistência de enfermagem de forma integral e individualiza em qualquer unidade de atendimento.

Salientamos ainda, que em nosso entendimento Levine considera a família como fator insubstituível, no que podemos considerar a comunicação do enfermeiro atuante na URPA com esta, auxiliando na diminuição da ansiedade, fator gerador do gasto de energia. Olhando para a unidade de recuperação pósanestésica, percebemos que atualmente os acompanhantes aguardam o retorno do paciente no quarto, pensamos que precisamos repensar esta "norma". É importante para o paciente e também para a família que exista uma comunicação efetiva, e sendo assim, consideramos que a família necessita ser comunicada do término da cirurgia, bem como, que receba o paciente na porta do centro cirúrgico no momento da saída, caso seja possível, e não apenas no quarto.

Consideramos que o ser humano interage em muitos níveis, ou seja, o nível psicológico não pode ser explicado em função do físico, nem o físico em função do social e nem o social em função do psicológico. Sendo que, cada um deles é igualmente válido e necessita ser considerado dentro de suas relações.

Acreditamos que com este estudo estaremos colaborando cientificamente para a implantação de um sistema de assistência na URPA que poderá ser utilizado e necessita estar em constante aprimoramento tendo em vista as especificidades de cada instituição e procedimento anestésico cirúrgico. Levine apud PICCOLI \& GALVÃO (2004) coloca que na medida em que o plano de cuidados é implementado, o enfermeiro deve observar as reações do paciente, onde são coletados dados para a fase de avaliação; acrescenta ainda, que durante a fase de implementação o enfermeiro é responsável pelos cuidados prestados ao paciente e que é esperado que este profissional possua habilidades necessárias para realizar as intervenções de enfermagem nos quatro princípios de conservação e que as intervenções de enfermagem visam apoiar e/ou promover a adaptação do paciente.

Finalizando, consideramos que a identificação de diagnósticos de enfermagem e conseqüente prescrição de enfermagem são absolutamente necessários e não podem sem implementadas apenas em função de normativas, sejam elas institucionais ou não, sendo assim, a nossa sugestão é de que haja sistematização da assistência de enfermagem perioperatória (pré, trans, URPA e pós-operatório) e que elas estejam fundamentadas em uma teoria de enfermagem que contemple as necessidades do paciente nos diversos momentos, atendendo as especificidades de cada um e que estejam articuladas entre as equipes das unidades de internações, CC e URPA. Nosso estudo teve a intenção de enfatizar a importância da assistência na URPA, mas que não haja fragmentação do cuidado, e sim, continuidade destes.

\section{REFERÊNCIAS BIBLIOGRÁFICAS}

ADAMES, R. C. Enfermagem perioperatória: diagnósticos de enfermagem no paciente idoso através da visita pré-operatória de enfermagem. Cascavel, 2002. Monografia (Graduação) - Universidade Estadual do Oeste do Paraná.

ALDRET, J. A. D. Apostanesthetic recovery score. Anesth anag: v. 49: p. 924-934, 1970. 
AVELAR, M. C. Q. A prática do enfermeiro de centro cirúrgico. São Paulo, 1991, 181 p., Tese (Doutorado), Escola de Enfermagem, Universidade de São Paulo, USP.

BELLO, C. N. Recuperação pós-anestésica - escalas de avaliação, princípios gerais. Rev. Centro Est. Anest. FMUSP. v, 9, p 4-5, 2000.

BRASIL. Leis, etc. Lei $n^{\circ} 7.498$ de 25 de junho de 1986. Lei do Exercício de Enfermagem. Diário Oficial da União. Brasília: 26 jun.1986, p.9273-5.

CARPENITO, L. J. Diagnósticos de enfermagem: aplicação e prática clínica. Trad. Ana Thorell. 6.ed. Porto Alegre: Artes Médicas, 1997.

Manual de diagnósticos de enfermagem. Trad. Ana Thorell. 9. ed. Porto Alegre, Artes Médicas, 2003.

CRUZ, D. A. L. M.; CRUZ I. C. Taxonomia os diagnósticos de enfermagem. Evolução e razões do uso. Acta Paulista, São Paulo, v.4. n.214, p.2834,1991.

FROST, E. A. M. Phostanesthesia care unit. Philadelphia: Mosby, 1992.

GEORGE, J. B. et al Teorias de enfermagem: fundamentos para a prática profissional. Porto Alegre: Artes Médicas, 2000.

HOFFER, J. L. Anestesia. In MEEKER, M.H.; ROTHROCK, J.C. Alexander: cuidados de enfermagem ao paciente cirúrgico. 10.ed. Rio de Janeiro: Guanabara Koogan, 1997. p.134-136.

HORTA, W. A. Processo de enfermagem. São Paulo: EDUSP, 1979.

KEARS, J. Management of intra operative ventilatory emergencies, refresher courses in anesthesilogy. ASA, v.17, 1989.

LEONARD, M. K. Myra Strin Levine. In: GEORGE,J.B. et al. Teorias de enfermagem: os fundamentos para a prática profissional. Porto Alegre: Artes Médicas, 1993. p.164 -173.

MANICA. J, et al. Anestesiologia. Princípios e técnicas. $2^{\mathrm{a}}$ ed. Porto Alegre: Artes médicas, 1994

NANDA. North American Nursing Diagnosis Association. Diagnóstico de enfermagem: definições e classificação. Trad. Ana Thorell. Porto Alegre: Artes médicas. 2002.

PENICHE, A. G. A influencia da ansiedade na resposta do paciente no período pós-operatório imediato. São Paulo, 1998, 81 p. Tese (Doutorado). Escola de Enfermagem da Universidade de São Paulo.

PICCOLI, M. Enfermagem Perioperatória: identificação dos diagnósticos de enfermagem na visita préoperatória fundamentada no modelo conceitual de Levine. Ribeirão Preto, 2000. 175 p. Dissertação (Mestrado). Escola de Enfermagem de Ribeirão Preto, Universidade de São Paulo.

PICCOLI, M.; GALVÃO, C.M. Enfermagem perioperatória: identificação dos diagnósticos de enfermagem na visita pré-operatória fundamentada no modelo conceitual de Levine. Cascavel: Edunioeste, 2004.

POSSARI, J.F. Assistência de enfermagem na recuperação pós-anestésica (RPA). São Paulo: látria, 2003.
REZENDE, J. M. Recuperação anestésica, 2000. [online] Disponível em http://usuarios.cultura.com.br/imrezende. Capturado em 29/03/2004.

RISNER, P. B. Diagnosis: analysis and synthesis of data. In: GRIFFITH-KENNEY, J. W.; CRISTENSEN, P.J. Nursing process: application of theories frameworks, and Models. $2^{\mathrm{a}}$ ed. Saint Louis: Mosby, 1986.

ROSSI, L. A. et al Diagnósticos de enfermagem do paciente no período pós-operatório imediato. Rev.Esc.Enf.USP v.34, n.2, p.154-64,.2000.

SMELTZER, S.C.; BARE, B.G. Tratado de enfermagem médico-cirúrgica. $9^{\mathrm{a}} \mathrm{ed}$. Rio de Janeiro: Guanabara Koogan, 2002.

TAVARES, L.M. Critérios de alta do paciente na SRPA. Fortaleza, 1999.

THORWALD, J. O século dos cirurgiões. Trad. Marina Guaspari. Curitiba: Hemus, 2002.

Texto recebido em 09/08/2004.

Publicação aprovada em 10/12/2004 